\title{
Layered double hydroxide and related catalysts for hydrogen production and a biorefinery
}

\author{
Wei Wang a,b, Zhenxin $\mathrm{Xu}^{\mathrm{a}}$, Zhanglong Guo ${ }^{\mathrm{a}, \mathrm{b}}$, Chengfa Jiang a, Wei Chu $\mathrm{a}^{\mathrm{a}, \mathrm{b}, *}$ \\ a Department of Chemical Engineering, Sichuan University, Chengdu 610065, Sichuan, China \\ b Sichuan Provincial Engineering Technology Center for Environmental Protection Catalytic Materials, Sichuan University, Chengdu 610064, Sichuan, \\ China
}

\section{A R T I C L E I N F O}

Article history:

Received 28 June 2014

Accepted 16 September 2014

Published 20 February 2015

\section{Keywords:}

Layered double hydroxide

Heterogeneous catalyst

Steam reforming

Hydrogen generation

Biorefinery

Transesterification

\section{A B S T R A C T}

Layered double hydroxides (LDHs) have received much attention for their unique properties. As solid catalysts, LDHs and their derivates have been widely studied and applied for their excellent catalytic performance. Several synthesis methods of LDHs were briefly introduced, and the applications of LDHs and related catalysts for hydrogen production and a biorefinery were emphasized in this article. The prospects for LDH related compounds in the synthesis of new materials and their catalytic application in green catalysis systems were also presented.

(C) 2015, Dalian Institute of Chemical Physics, Chinese Academy of Sciences. Published by Elsevier B.V. All rights reserved.

\section{Introduction}

Layered double hydroxides (LDHs) are layered anionic clays also known as hydrotalcite-like compounds (HTLCs). They are new inorganic functional materials with positively charged brucite-like lamellas and charge-balancing anions and solvation molecules in the interlayer region. The lamellar structure is constructed with octahedrons by sharing their edges with divalent and trivalent metal cations in the center and six hydroxide ions at vertexes [1,2], as shown in Fig. 1.

LDHs have attracted considerable interest in recent years due to their unique structure and properties, including exchangeable lamellar anions, controllable basicity, tunable composition, and uniform deposition of the active metal $[3,4]$. Homogeneously dispersed mixed metal oxides can be obtained by a controlled thermal decomposition of LDH precursors. These oxides have many special characteristics, such as high specific surface areas, basic character, high dispersion of the metallic phase, thermal stability against sintering, and capacity to regenerate the original layered structure $[5,6]$. Therefore, LDHs and their derivatives have been widely used as heterogeneous basic catalysts in many fields, such as clean energy and pollution control $[7,8]$.

LDHs have received much attention for their properties and catalytic performance. Recent progress in the synthesis of LDHs is summarized with a special focus on the application of LDHs and derivates as catalysts for $\mathrm{H}_{2}$ production and a biorefinery in this work. We expect that more efforts will be devoted to the special layer structure and properties of LDHs, which are significant for the design of new materials $[9,10]$.

\footnotetext{
*Corresponding author. Tel: +86-28-85403836; Fax: +86-28-85461108; E-mail: chuwei1965@scu.edu.cn, chuwei1965scu@163.com This work was supported by the National Basic Research Program of China (973 Program, 2011CB201202). 


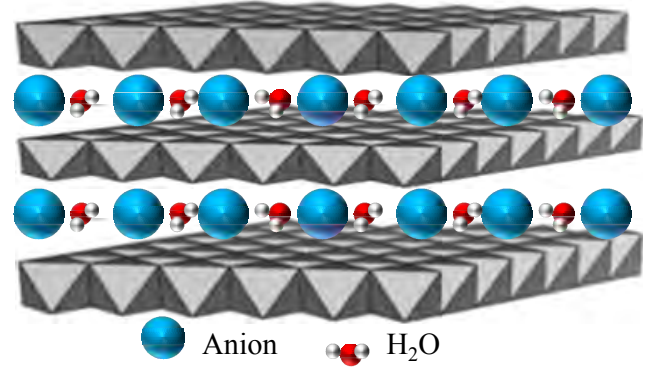

Fig. 1. Structure illustration of LDHs.

\section{Synthesis methods of LDHs}

The preparation methods of LDHs include co-precipitation method, urea hydrolysis process, anion exchange, and roasting recovery technique. The co-precipitation method is the most widely used process to prepare LDHs [11,12]. For this method, solution A and solution B are prepared first before co-precipitation. Solution A contains different metal nitrate hexahydrate with the proper molar ratio, and solution $\mathrm{B}$ is usually a mixture solution of $\mathrm{Na}_{2} \mathrm{CO}_{3}$ and $\mathrm{NaOH}$. Then, solution $\mathrm{A}$ and solution $\mathrm{B}$ are simultaneously added dropwise to a vessel containing deionized water with vigorous stirring. During this process, the slurry is kept at a constant $\mathrm{pH}$ by controlling the dripping speed of the solution. After aging for a period of time, the precipitate obtained is separated from the mother solution, rinsed with deionized water, and appropriately dried to obtain the $\mathrm{LDH}$ $[13,14]$. Yan et al. [13] successfully synthesized a series of LDH precursors used for the dehydration of biomass-derived fructose into the platform chemical 5-hydroxymethylfurfural by this method. This technology includes the low supersaturation method and high supersaturation method [15]. Usually, the aging process is combined with a hydrothermal or microwave treatment $[16,17]$. The crystallinity of the LDHs can be improved, but the former is time consuming and the crystals always have a large particle size, while the latter is time saving and the crystals are relatively small with a uniform distribution.

The urea hydrolysis process usually employs urea as precipitant. By controlling the heating rate, the urea decomposition rate can be controlled, and the solution can be kept at a constant $\mathrm{pH}$. Through this way, the sedimentation rate of the catalysts can be controlled [18]. In brief, solid urea is added to an aqueous solution containing metal nitrates with the desired molar ratio, until the urea to metal molar ratio reaches the desired value. The solution obtained is usually kept stirred at a certain temperature in a thermostatic reactor equipped with a coolant. The precipitates are filtered, washed, and then dried at the set temperature, and finally the LDH precursors are obtained $[18,19]$. Compared to the co-precipitation method, this procedure can be operated more easily and is time saving. Therefore, it has been widely used. In our previous works, Yu et al. [19] successfully synthesized the NiCuMgAl LDH precursors for ethanol steam reforming using this method. The XRD patterns of the Ni..5 $\mathrm{Mg}_{2.5-x} \mathrm{Cu}_{x} \mathrm{Al}$ precursors are shown in Fig. 2. This method is also combined with a hydrothermal or micro-

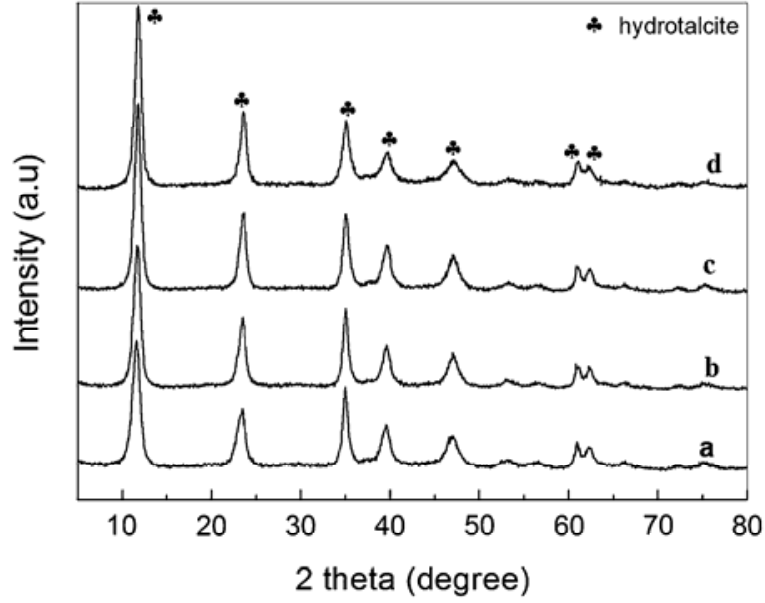

Fig. 2. XRD patterns of $\mathrm{LDH}$ precursors. (a) $\mathrm{Ni}_{0.5} \mathrm{Mg}_{2.5} \mathrm{Al}$; (b) $\mathrm{Ni}_{0.5} \mathrm{Cu}_{0.05} \mathrm{Mg}_{2.45} \mathrm{Al}$; (c) $\mathrm{Ni}_{0.5} \mathrm{Cu}_{0.1} \mathrm{Mg}_{2.4} \mathrm{Al}$; (d) $\mathrm{Ni}_{0.5} \mathrm{Cu}_{0.25} \mathrm{Mg}_{2.25} \mathrm{Al}$. Reproduced from Ref. [19] with kind permission from Springer Science and Business Media.

wave treatment to improve the morphology of the LDHs [20,21]. Recently, Deng et al. [22] synthesized a series of LDH precursors using urea as precipitating agent combined with a microwave-hydrothermal treatment. The resulting material had a narrow particle size distribution. Scanning electron microscopy images of LDH and calcined LDH are shown in Fig. 3.

The anion exchange technique takes advantage of the exchangeability of the interlayer anions to realize the exchange of the interlayer anions with other desired anions. Usually, LDH precursors synthesized by the methods given above are suspended in a solution containing the desired anions under mild conditions. A few hours later, LDHs with the desire anion can be obtained [18,23]. Recently, a binary system of SbШ, an important alternative for Leishmaniasis chemotherapy, was prepared by Menezes et al. [24] using MgAl LDHs as a nanocarrier via ion exchange. The roasting recovery method makes full use of the "memory effect" of LDHs. When the mixed oxides, calcined LDHs, are put back into a solution containing the required anions with a certain $\mathrm{pH}$, they can reconstruct the original lamellar structure after a period of time [25,26]. Álvarez et al. [5] found that the rehydrated LDHs had many basic Brönsted sites. Therefore, they showed excellent catalytic activity for the transesterification of glycerol. Meanwhile, Sun et al. [26] reported that F- modified CuNiAl LDHs synthesized by this method had high activity for the selective oxidation of toluene to benzyl alcohol.

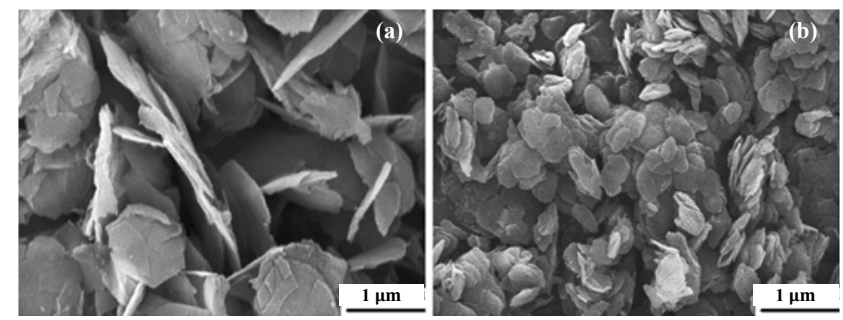

Fig. 3. SEM images of LDH (a) and calcined LDH at $773 \mathrm{~K}$ for $6 \mathrm{~h}$ (b). Reprinted with permission from Ref. [22]. Copyright 2011 Elsevier. 
In addition, some unconventional preparation methods have also been reported, such as the reverse microemulsion method [27] and the sol-gel method [28].

\section{Catalytic applications of LDHs and related catalysts}

\subsection{Catalysis for $\mathrm{H}_{2}$ production}

Hydrogen, a clean energy, has attracted attention for its development and utilization in the field of clean energy $[29,30]$. Due to their high hydrogen content, methane and low carbon alcohols, such as methanol and ethanol, have been widely investigated for their catalytic reforming or oxidation for $\mathrm{H}_{2}$ production.

\subsubsection{Methane reforming or methane oxidation}

Steam reforming of methane is an economic way to produce hydrogen. It is generally accepted that methane and steam are first catalytically reformed into $\mathrm{CO}$ and $\mathrm{H}_{2}$ (Eq. (1)). Usually, the water-gas shift reaction is introduced to further convert $\mathrm{CO}$ into $\mathrm{CO}_{2}$ (Eq. (2)). However, the methane conversion and hydrogen productivity are limited by the thermodynamic equilibrium of the reverse methanation (Eqs. (1) and (3)) and water-gas shift reactions (Eq. (2)) [31,32].

$$
\begin{array}{cc}
\mathrm{CH}_{4}+\mathrm{H}_{2} \mathrm{O} \leftrightarrow \mathrm{CO}+3 \mathrm{H}_{2} & \Delta H^{\theta_{298 K}}=+205.9 \mathrm{~kJ} / \mathrm{mol} \\
\mathrm{CO}+\mathrm{H}_{2} \mathrm{O} \leftrightarrow \mathrm{CO}_{2}+\mathrm{H}_{2} & \Delta H^{\theta_{298 K}}=-41.1 \mathrm{~kJ} / \mathrm{mol} \\
\mathrm{CH}_{4}+2 \mathrm{H}_{2} \mathrm{O} \leftrightarrow \mathrm{CO}_{2}+4 \mathrm{H}_{2} & \Delta H^{\theta_{298 K}}=+164.7 \mathrm{~kJ} / \mathrm{mol}
\end{array}
$$

To solve this problem, sorption-enhanced steam methane reforming (SE-SMR) based on the idea of shifting the thermodynamic equilibrium of the reactions towards the hydrogen product direction by selectively adsorbing $\mathrm{CO}_{2}$ on an effective adsorbent was proposed in recent years. Broda et al. [31] investigated SE-SMR over a mixture catalyst containing a Ni-LDH-derived catalyst and a synthetic, calcium aluminate supported Ca-based carbon dioxide adsorbent. The combination of Ni-LDH-derived catalyst and the synthetic $\mathrm{CO}_{2}$ adsorbent produced high purity $\mathrm{H}_{2}$. Equilibrium conversion of me- thane was achieved with the purity of hydrogen up to 99 vol\% (dry and without the inert component) at a reaction temperature of $550{ }^{\circ} \mathrm{C}$ and a steam to methane ratio of 4 . Ca-based pellets showed excellent performance in the reaction, which was attributed to their stable nanostructured morphology, as shown in Fig. 4. The homogeneously dispersed mayenite substantially retarded the thermal sintering of $\mathrm{CaO}$ grains. At almost the same time, Chanburanasiri et al. [32] reported that $\mathrm{K}_{2} \mathrm{CO}_{3}$-promoted LDHs with in situ $\mathrm{CO}_{2}$ capture were also an efficient catalyst for SE-SMR. They noted that the $\mathrm{CO}_{2}$ adsorption type was diverse among the different LDHs, which resulted in different sorption-enhanced characteristics. Under optimized conditions, high purity $\mathrm{H}_{2}$ production was also obtained.

Compared to the conventional methane steam reforming process, autothermal reforming (ATR) of methane has also received much attention for higher energy efficiency and lower energy requirements [33,34]. Ni-based catalysts prepared from LDH precursors showed high catalytic activity. However, they are susceptible to carbon deposition and may be oxidized at low temperatures. It has been reported that the doping of a small amount of noble metals can significantly improve catalyst stability and activity [33]. Nagaoka et al. [33] found that NiRh alloy particles were formed in a NiRh/MgAl catalyst and $\mathrm{Rh}$ enhanced the dispersion of Ni nano-particles on the surface of the NiRh alloy, which were critical for the catalytic activity. Due to the $\mathrm{H}_{2}$ spillover effect from $\mathrm{Rh}$ on the $\mathrm{NiRh}$ alloy, the stability of the NiRh/MgAl catalyst against oxidation was enhanced. Takehira et al. [35] investigated the structure-activity relationship of the $\mathrm{Ni} / \mathrm{MgAl}$ catalysts for ATR of methane. Catalysts with a high surface area of $150 \mathrm{~m}^{2} / \mathrm{g}$-cat were successfully prepared by the co-precipitation method followed by thermal decomposition and $\mathrm{H}_{2}$ reduction. The dispersion of $\mathrm{Ni}$ was repeatedly enhanced, which was attributed to the formation of a Mg-O-Ni solid solution. Highly dispersed Ni active centers with a small particle size about $8 \mathrm{~nm}$ were obtained after $\mathrm{H}_{2}$ reduction, and the catalyst showed relatively high stability compared with the catalysts prepared by the conventional impregnation

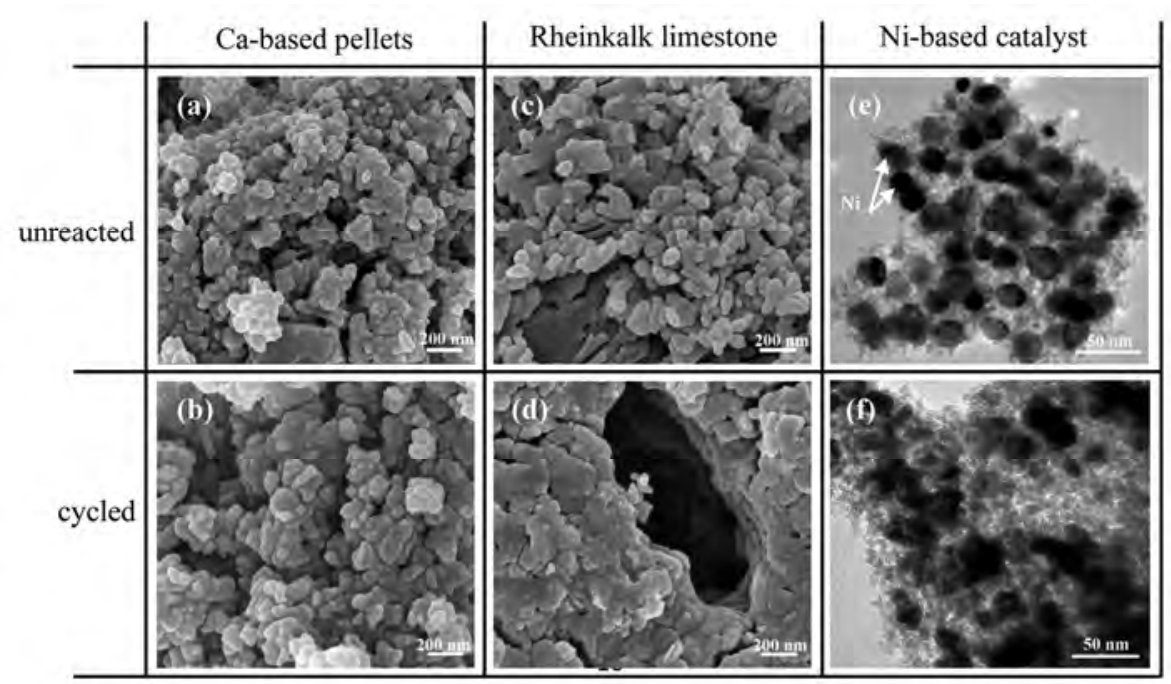

Fig. 4. HR-SEM and TEM images of unreacted and cycled (10 cycles) materials. (a,b) Ca-based pellets; (c,d) Rheinkalk limestone; (e,f) Ni-based catalyst. Reprinted with permission from Ref. [31]. Copyright 2013 American Chemical Society. 


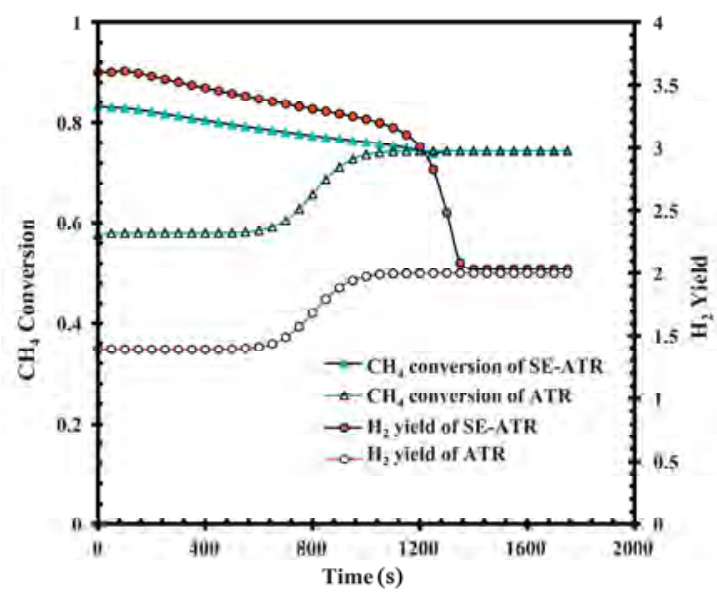

Fig. 5. Dynamic profiles of effluent $\mathrm{CH}_{4}$ conversion and $\mathrm{H}_{2}$ yield obtained in ATR and SE-ATR. Reprinted with permission from Ref. [34]. Copyright 2011 Elsevier.

method. Recently, Halabi et al. [34] for the first time combined the sorption-enhanced concept together with the ATR of methane at low temperature and a relatively low pressure. They investigated the SE-ATR using K-promoted LDHs as sorbent combined with a conventional $\mathrm{Ni} / \mathrm{MgO}$ catalyst. The SE-ATR showed advantages over the ATR process (Fig. 5). The $\mathrm{CH}_{4}$ conversion and $\mathrm{H}_{2}$ purity were up to $85 \%$ and $96 \%$, respectively, with a low level of $\mathrm{CO}+\mathrm{CO}_{2}$ impurities less than $0.03 \%$ at the experiment conditions in the SE-ATR process. However, compared with lithium zirconate, the low adsorption capacity of LDHs was still a limiting factor in the reaction.

$$
\begin{aligned}
\mathrm{CH}_{4}+1 / 2 \mathrm{O}_{2} \leftrightarrow \mathrm{CO}+2 \mathrm{H}_{2} & \Delta H^{\theta_{2}}{ }_{298 \mathrm{~K}}=-36.0 \mathrm{~kJ} / \mathrm{mol} \\
\mathrm{CH}_{4}+2 \mathrm{O}_{2} \leftrightarrow \mathrm{CO}_{2}+2 \mathrm{H}_{2} \mathrm{O} & \Delta H^{\theta} 298 \mathrm{~K}=-802.7 \mathrm{~kJ} / \mathrm{mol}
\end{aligned}
$$

On the other hand, methane partial oxidation (Eq. (4)) is also a promising technology which shows high conversion and selectivity and works with short contact times [36]. Cesar et al. [36] studied the catalytic performance of NiMgAl and RhNiMgAl catalysts in the partial oxidation of methane. The results indicated that the reducibility of $\mathrm{Ni}$ can be improved by $\mathrm{Rh}$ and its stability was increased against carbon deposition, which was consistent with the result reported before [33]. As mentioned above, the preparation procedure always influenced the interactions between the metal and the support, which play an important role on the catalyst properties. Basile et al. [37] found that the catalytic performance can be improved by a microwave-hydrothermal treatment (MWHT) compared with the conventional co-precipitation method (Fig. 6). They revealed that the MWHT not only improved the crystallinity of the LDHs precursor, but also modified the catalyst properties. A smaller oxide and spinel crystallite size were obtained for the MW-aged sample compared with those obtained by the conventional co-precipitation method after calcination. Furthermore, due to the better dispersion of the active metal in the oxide matrix, the stability of $\mathrm{Ni}$ against reduction was enhanced. Meanwhile, Tanasoi et al. [38] observed that mesoporous $\mathrm{CuMgAl}$ mixed oxide with high surface area derived from LDH precursors was active for the total oxidation of methane (Eq. (5)). $\mathrm{CuO}$ and $\mathrm{CuAl}_{2} \mathrm{O}_{4}$ phases were present in the calcined

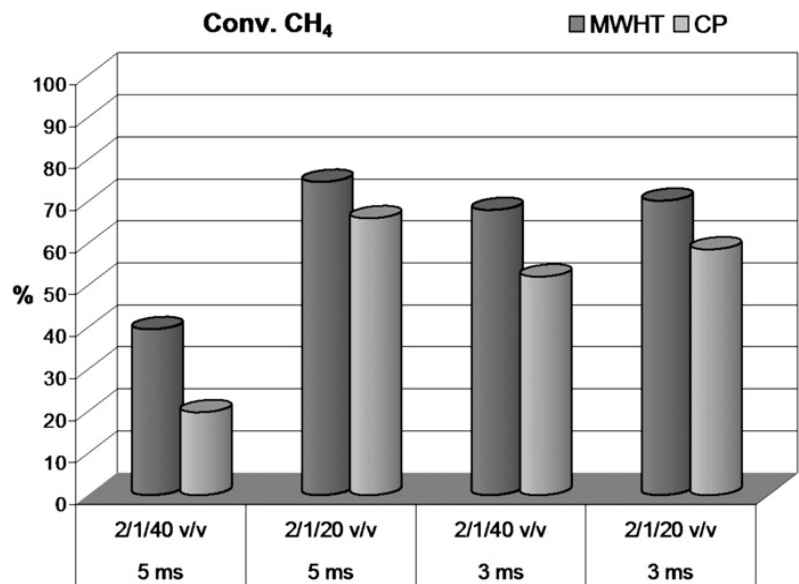

Fig. 6. Methane conversion for the $\mathrm{Ni}_{10} \mathrm{Mg}_{61} \mathrm{Al}_{29}$ catalysts prepared using the conventional co-precipitation method and MWHT during the tests by feeding diluted conditions at $T_{\text {oven }}=500{ }^{\circ} \mathrm{C}$. Reprinted with permission from Ref. [37]. Copyright 2010 Elsevier.

catalysts, which increased the dispersion of $\mathrm{CuO}$. The total conversion of methane can be achieved at $525^{\circ} \mathrm{C}$ below, and no CO was detected at the exhaust under all the experimental conditions.

\subsubsection{Low carbon alcohol reforming}

Steam reforming of alcohols, mainly methanol and ethanol vapor reforming, is considered a favorable process for $\mathrm{H}_{2}$ production. The major challenge for alcohol reforming is to produce high purity $\mathrm{H}_{2}$ with ppm level of $\mathrm{CO}$ content. The overall reaction of steam reforming of methanol can be written as

$$
\begin{gathered}
\mathrm{CH}_{3} \mathrm{OH}(\mathrm{g})+\mathrm{H}_{2} \mathrm{O}(\mathrm{g}) \rightarrow \mathrm{CO}_{2}(\mathrm{~g})+3 \mathrm{H}_{2}(\mathrm{~g}) \\
\Delta H^{\theta}{ }_{298 \mathrm{~K}}=+49.5 \mathrm{~kJ} / \mathrm{mol}
\end{gathered}
$$

Catalysts derived from $\mathrm{LDH}$ precursors were extensively studied because the homogeneous stable oxide composite inhibited the surface active phase from sintering and, as a consequence, long term stability with high activity was achieved. $\mathrm{Cu}$-based catalysts are frequently studied for the steam reforming of alcohols due to their high selectivity and activity $[39,40]$. Tang et al. [40] found that the catalyst derived from a CuZnAl LDH provided excellent activity and stability for methanol steam reforming, which was attributed to the formation of the $\mathrm{CuAl}_{2} \mathrm{O}_{4}$ spinel phase during the decomposition of $\mathrm{CuZnAl}$ LDH. They revealed that the spinel phase played a key role in isolating and stabilizing the $\mathrm{Cu}$ particles on the catalyst surface. A CuZnAl catalyst prepared from metal acetates showed the best catalytic activity and stability, and converted $\mathrm{a}_{2} \mathrm{O} / \mathrm{CH}_{3} \mathrm{OH}$ (1.3/1, mol/mol) mixture into $\mathrm{H}_{2}$ with a $\mathrm{CO}$ concentration as low as $0.05 \%$ at $250{ }^{\circ} \mathrm{C}$ or $0.005 \%$ at $210{ }^{\circ} \mathrm{C}$ and maintained its activity ( $>98 \%$ ) with a CO concentration of $0.03 \%-0.05 \%$ in the dry product gas for the entire 100 -h test at $250{ }^{\circ} \mathrm{C}$. Meanwhile, they observed that catalysts synthesized using sulfates and chlorides as $\mathrm{Cu}$ and $\mathrm{Zn}$ sources were inactive due to the toxic effect of $\mathrm{S}$ and $\mathrm{Cl}$ residues.

Ethanol steam reforming was also widely studied because of the potentially high yield to hydrogen. Eq. (7) represents the steam reforming of ethanol. 


$$
\begin{gathered}
\mathrm{C}_{2} \mathrm{H}_{5} \mathrm{OH}(\mathrm{g})+3 \mathrm{H}_{2} \mathrm{O}(\mathrm{g}) \leftrightarrow 2 \mathrm{CO}_{2}(\mathrm{~g})+6 \mathrm{H}_{2}(\mathrm{~g}) \\
\Delta H^{\theta_{298}}=+173.3 \mathrm{~kJ} / \mathrm{mol}
\end{gathered}
$$

$\mathrm{Ni}$ is commonly employed as the active phase for ethanol steam reforming for its low cost and high activity, but it also favors the methanation reaction (Eq. (1)), which limits the $\mathrm{H}_{2}$ yield. Previous studies found that $\mathrm{Cu}$ can limit the latter reaction by suppressing CO dissociation on $\mathrm{Ni}[19,41]$. In our previous works, Yu et al. [19] successfully synthesized NiCuMgAl catalysts derived from the corresponding LDH precursors by the urea hydrolysis method. The addition of small amounts of $\mathrm{Cu}$ increased surface $\mathrm{Ni}$ species and the reducibility of $\mathrm{Ni}^{2+}$ (Fig. 7). The $\mathrm{Ni}_{0.5} \mathrm{Cu}_{0.1} \mathrm{Mg}_{2.4} \mathrm{Al}$ catalyst exhibited strong resistance to coke formation and sintering of Ni particles, and showed high activity and stability with no apparent deactivation during $20 \mathrm{~h}$ on stream at $700{ }^{\circ} \mathrm{C}$. Recently, the sorption-enhanced reaction process has also been extensively studied. Cunha et al. [42] investigated the steam reforming and sorption enhanced steam reforming of ethanol over $\mathrm{Cu}, \mathrm{Zn}, \mathrm{Al}$ materials. The $\mathrm{CuZnAl}$ catalyst derived from LDH precursor showed the highest activity and selectivity with satisfying stability among all the samples. Due to good interaction of $\mathrm{CO}_{2}$ and the presence of a $\mathrm{ZnO}$ phase, a sorption enhanced steam reforming of ethanol phenomena was observed. After that, they successfully synthesized a new multifunctional K-Ni-Cu-HTLC hybrid material for $\mathrm{H}_{2}$ production [43]. A desired sorption-enhanced reaction process was achieved using a $\mathrm{K}$ promoter together with the hydrotalcite-like material for $\mathrm{CO}_{2}$ adsorption. They reported that $\mathrm{Cu}$ was favored for the ethanol dehydrogenation (Eq. (8)) and the water-gas shift (Eq. (2)) reaction, while $\mathrm{Ni}$ was suitable for acetaldehyde decomposition (Eq. (9)) and steam reforming of methane (Eq. (1)). At $773 \mathrm{~K}$, using the water to ethanol molar ratio of 10 , a high purity hydrogen stream (99.8 mol\% on dry basis) was obtained during the prebreakthrough period.

$$
\mathrm{C}_{2} \mathrm{H}_{5} \mathrm{OH}(\mathrm{g}) \leftrightarrow \mathrm{C}_{2} \mathrm{H}_{4} \mathrm{O}(\mathrm{g})+\mathrm{H}_{2}(\mathrm{~g}) \quad \Delta H^{\theta_{298 K}}=+68.4 \mathrm{~kJ} / \mathrm{mol}
$$

$\mathrm{C}_{2} \mathrm{H}_{4} \mathrm{O}(\mathrm{g}) \leftrightarrow \mathrm{CH}_{4}(\mathrm{~g})+\mathrm{CO}(\mathrm{g}) \quad \Delta H^{\theta_{2}}{ }_{28 \mathrm{~K}}=-18.8 \mathrm{~kJ} / \mathrm{mol}$

Ethanol autothermal reforming was also widely studied $[44,45]$. Huang et al. [45] investigated the catalytic performance

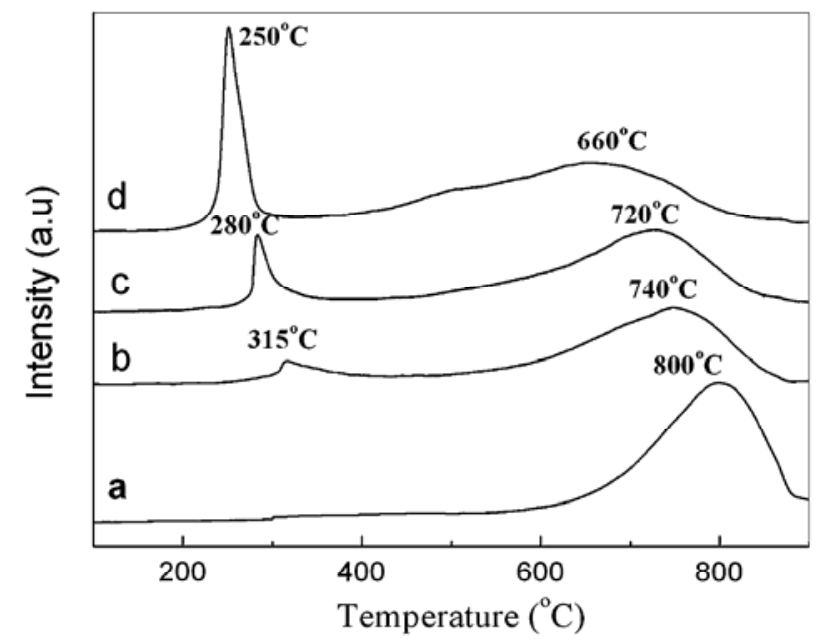

Fig. 7. TPR patterns of the layered double hydroxide precursors. (a) $\mathrm{Ni}_{0.5} \mathrm{Mg}_{2.5} \mathrm{Al}$; $\quad$ (b) $\quad \mathrm{Ni}_{0.5} \mathrm{Cu}_{0.05} \mathrm{Mg}_{2.45} \mathrm{Al}$; $\quad$ (c) $\mathrm{Ni}_{0.5} \mathrm{Cu}_{0.1} \mathrm{Mg}_{2.4} \mathrm{Al}$; $\quad$ (d) $\mathrm{Ni}_{0.5} \mathrm{Cu}_{0.25} \mathrm{Mg}_{2.25} \mathrm{Al}$. Reproduced from Ref. [19] with kind permission from Springer Science and Business Media. of $\mathrm{Co}_{0.3} \mathrm{Mg}_{2.7} \mathrm{Al}_{1-x} \mathrm{Fe}_{x} \mathrm{O}_{4.5 \pm \delta}$ in autothermal reforming of bio-ethanol for $\mathrm{H}_{2}$ production. Due to the synergism of $\mathrm{Co}$ and $\mathrm{Fe}$, the $\mathrm{Co}_{0.3} \mathrm{Mg}_{2.7} \mathrm{Al}_{0.9} \mathrm{Fe}_{0.1} \mathrm{O}_{4.5 \pm \delta}$ catalyst showed better performance compared with the iron-free catalyst with the conversion of ethanol being nearly $100 \%$ and the $\mathrm{H}_{2}$ yield above 3.2 $\mathrm{mol} \mathrm{H}_{2} / \mathrm{mol} \mathrm{C}_{2} \mathrm{H}_{5} \mathrm{OH}$ throughout the 30 -h test.

\subsection{Catalysts for a biorefinery}

A biorefinery provides a possible solution to the challenges from the diminution of oil and the increase of $\mathrm{CO}_{2}$ emission, while it opens a new way to the sustainable production of fuels and chemicals from vast renewable biomasses [46]. LDHs and their derivatives show good application prospects in the catalysis in a biorefinery because of important advantages, such as suitable basicity, high surface area, and pore volume, improved selectivity under mild conditions and easy separation from the reaction mixtures.

Biodiesel, a mixture of long chain fatty acid methyl esters (FAME), is a diesel fuel that could solve environmental concerns and the limited resources of fossil fuels. At present, biodiesel is mainly produced by the transesterification of renewable biological triglyceride sources (plant oils and animal fats) with alcohols (methanol or ethanol) using homogeneous basic catalysts (Scheme 1) [47]. However, this homogeneous process has severe pollution and corrosion problems. Recently, LDHs and their derivates have been widely used as solid basic catalyst for biodiesel production. Quite good results have been obtained. It has been reported that the catalytic activity is associated with the catalyst basicity. With the increase of the Mg molar ratio, the basicity of the catalyst can be enhanced [48-50]. Silva et al. [48] systematically evaluated the effect of the $\mathrm{Mg} / \mathrm{Al}$ ratio on the basicity and catalytic activity for the methanolysis of soybean oil. They indicated that the LDH catalyst with a $\mathrm{Al} /(\mathrm{Mg}+\mathrm{Al})$ molar ratio of 0.33 contained many medium strength basic sites, which were preferred for the reaction. The conversion of soybean oil was up to $90 \%$ when the reaction was carried out at $230{ }^{\circ} \mathrm{C}$ with a methanol to oil molar ratio of 13 , a catalyst loading $5 \mathrm{wt} \%$, and 1 -h reaction time. This differed from that observed by Martins et al. [49]. They found that an $\mathrm{LDH}$ prepared by the co-precipitation method with a $\mathrm{Mg} / \mathrm{Al}$ molar ratio of 3 and calcined at $450{ }^{\circ} \mathrm{C}$ had numerous moderately basic sites, as displayed in Fig. 8 . The highest intensity peak indicated the presence of numerous moderately basic sites. The results showed that the highest FAME conversion of about $94.8 \%$ was achieved using a methanol to oil molar ratio of 20 , and $5 \mathrm{wt} \%$ catalyst for 10 -h. Recently, Liu et al. [51] indicated that during the thermal decomposition of LDHs, the basic sites of LDHs changed from the $\mathrm{OH}$ groups to $\mathrm{M}^{\mathrm{n}+} \mathrm{O}^{2-}(\mathrm{M}=\mathrm{Zn}$

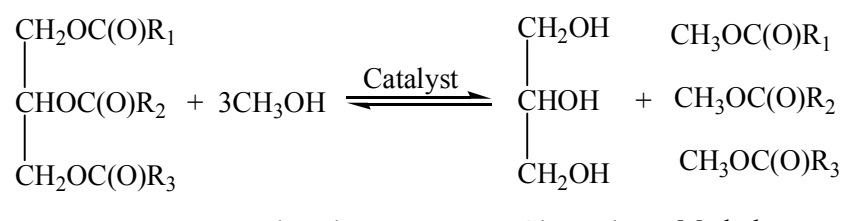

Triglycerides Methanol Glycerol Methyl esters

Scheme 1. Triglycerides transesterification reaction with methanol. 


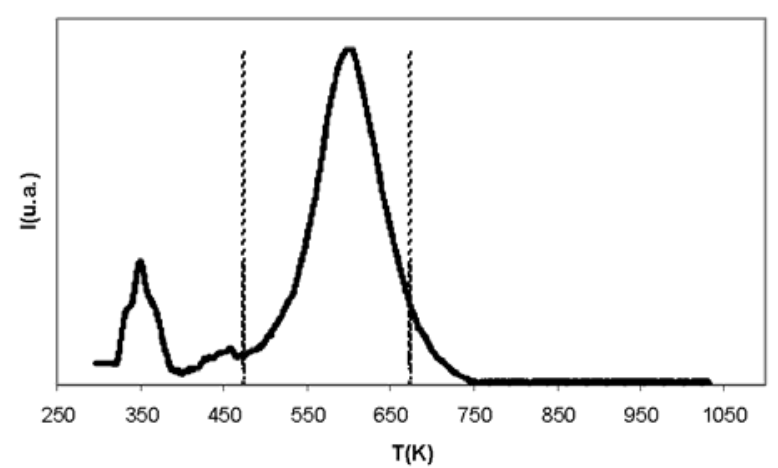

Fig. 8. $\mathrm{CO}_{2}$-TPD profile for the hydrotalcite after calcination at $450{ }^{\circ} \mathrm{C}$ $(\mathrm{Mg} / \mathrm{Al}=3)$. Reprinted with permission from Ref. [49]. Copyright 2013 AIDIC Servizi S.r.l.

or $\mathrm{Al}$ ) pairs and isolated $\mathrm{O}^{2-}$ ions. Therefore, the basicity of the catalyst was enhanced, which benefited the transesterification. At the same time, Helwani et al. [52] pointed out that an LDH calcined at $850{ }^{\circ} \mathrm{C}$ possessed a higher surface area $(124.30$ $\mathrm{m}^{2} / \mathrm{g}$ ), suitable pore diameter and more medium strength basic sites than that calcined at a low temperature. This sample favored the chemical reaction due to the high electronegativity. The highest conversion of jatropha curcas oil was up to $75.2 \%$ under the experimental conditions. They revealed that it was not the leachability of $\mathrm{Mg}^{2+}$ and $\mathrm{Al}^{3+}$ in the liquid products but the heterogeneity of the surface basicity that was a major concern, possibly due to the weakened Lewis basic sites $\left(\mathrm{O}^{2-}\right)$.

LDHs containing transition metals as a solid base catalyst for this reaction have also been reported [53,54]. The addition of transition metals enhanced the formation of $\mathrm{Mg}^{2+-} \mathrm{O}^{2-}$ and $\mathrm{Al}^{3+-} \mathrm{O}^{2-}$ pairs, which decreased the surface area of the catalyst but increased the basicity, as listed in Table 1. Meanwhile, the pore size of the catalysts was also increased, for instance, the pore size increased from 8 to $10 \mathrm{~nm}$ for the catalysts containing $\mathrm{Ni}^{2+}$ [54]. However, due to the loss of active metal ions, the reusability and stability of these catalysts were low [53]. It is worth mentioning that Liu et al. [51] indicated that a dehydrated $\mathrm{ZnAl} \mathrm{LDH}$ obtained at $200{ }^{\circ} \mathrm{C}$ was active for the methanolysis of soybean oil. It exhibited high activity with a biodiesel yield of approximately 76\%, and after about $150 \mathrm{~h}$ the catalyst showed no deactivation, as shown in Fig. 9.

On the other hand, a more recent investigation demonstrated that structured catalysts had good potential for improving the synthesis of biodiesel by transesterification. Gao et al. [55] used KF/Ca-Al LDH as the basic catalyst for the transesterification of methanol with palm oil to produce biodiesel. The fatty acid methyl esters yield reached 99.74\% and $97.14 \%$ under the optimal conditions and only needed 3 and $1 \mathrm{~h}$, re-

Table 1

Textural properties of the materials.

\begin{tabular}{lccc}
\hline Sample & Surface area $\left(\mathrm{m}^{2} / \mathrm{g}\right)$ & $\mathrm{CO}_{2}$ adsorption $(\mathrm{mmol} / \mathrm{g})$ & Ref. \\
\hline $\mathrm{Mg}_{3} \mathrm{Al}$ & 185.0 & 0.16 & {$[53]$} \\
$\mathrm{MgAlFe}_{6}$ & 124.5 & 0.18 & {$[53]$} \\
$\mathrm{MgAlFe}_{15}$ & 100.1 & 0.24 & {$[53]$} \\
$\mathrm{MgAlNi}_{4}$ & 105.5 & 0.19 & {$[54]$} \\
MgAlNi $_{16}$ & 91.6 & 0.25 & {$[54]$} \\
\hline
\end{tabular}

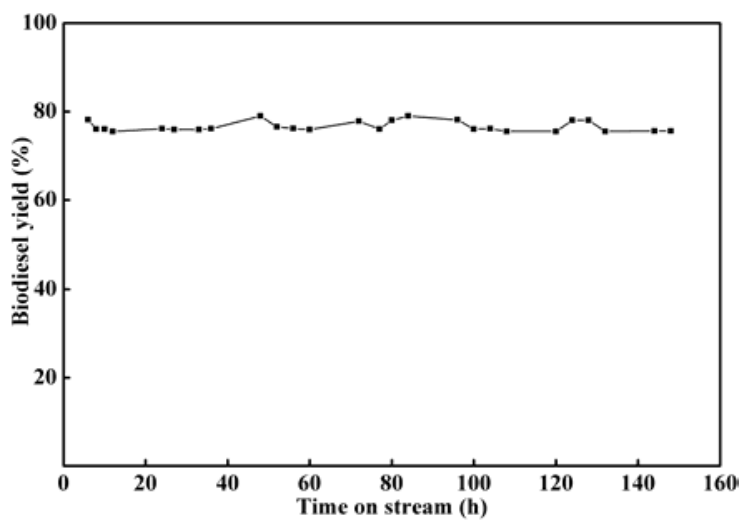

Fig. 9. Stability of $\mathrm{ZnAl}_{473 \mathrm{~K}}$ catalyst for transesterification. Reaction conditions: WHSV $=1.0 \mathrm{~h}^{-1}, 140{ }^{\circ} \mathrm{C}, 1.7 \mathrm{MPa}$, feed volume ratio of methanol to soybean oil 1:1. Reproduced from Ref. [51] with permission of The Royal Society of Chemistry.

spectively. Meanwhile, metallic monoliths based on MgAl LDHs were synthesized for the methanolysis of sunflower oil by Reyero et al. [56]. This catalyst gave $62 \%-77 \%$ oil conversion after $10 \mathrm{~h}$ under mild conditions.

The growing production of biodiesel generates a large surplus of glycerol as a major byproduct. Therefore, the catalytic conversion of glycerol to high value-added products has been widely studied. The transesterification of glycerol with dimethyl carbonate to produce glycerol carbonate under mild conditions is an attractive way (Scheme 2) [50,57]. Zheng et al. [50] found that $\mathrm{Mg}$ - $\mathrm{Al}$ layered double hydroxides with a $\mathrm{Mg} / \mathrm{Al} \mathrm{mo-}$ lar ratio of 2 , after it was calcined at $400{ }^{\circ} \mathrm{C}$ for $4 \mathrm{~h}$, had a large surface area (158.5 $\left.\mathrm{m}^{2} / \mathrm{g}\right)$, mid-range density of basic sites $\left(1.10 \mu \mathrm{mol} / \mathrm{m}^{2}\right)$, and large pore channels, which were suitable for this reaction. The catalyst exhibited high activity with $66.9 \%$ of glycerol conversion and $97.1 \%$ of selectivity of glycerol carbonate at $70{ }^{\circ} \mathrm{C}$ for $3 \mathrm{~h}$. Meanwhile, this catalyst showed good reusability (Fig. 10). The calcined LDHs can be reconstructed back to the original layer structure due to their "memory effect". The reconstruction of the LDHs by exposing the decomposed sample to water under a $\mathrm{CO}_{2}$ free atmosphere generated many Brönsted base sites in the interlayer, which favored the transesterification reaction $[58,59]$. This has been confirmed by Álvarez et al. [5,59]. Recently, Liu et al. [60] reported that transition metal doping enhanced the base strength of the catalyst, which improved the catalytic performance. On the other hand, the catalytic oxidation of glycerol to glyceric acid and dihydroxyacetone and hydrogenolysis of glycerol to propanediols are other important ways to convert glycerol into value-added products. Tongsakul et al. [61] investigated the catalytic oxidation of glycerol in a base-free aqueous solution under ambient conditions over bimetallic $\mathrm{Pt}_{x} \mathrm{Au}_{y}$-starch/HTLC catalysts. The Pt ${ }_{60} \mathrm{Au}_{40}$-starch/HTLC was efficient for the selec-

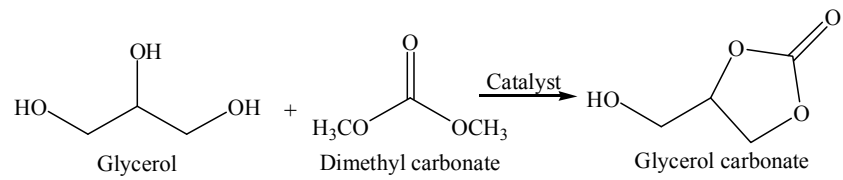
Scheme 2. Glycerol transesterification reaction with dimethyl carbonate. 


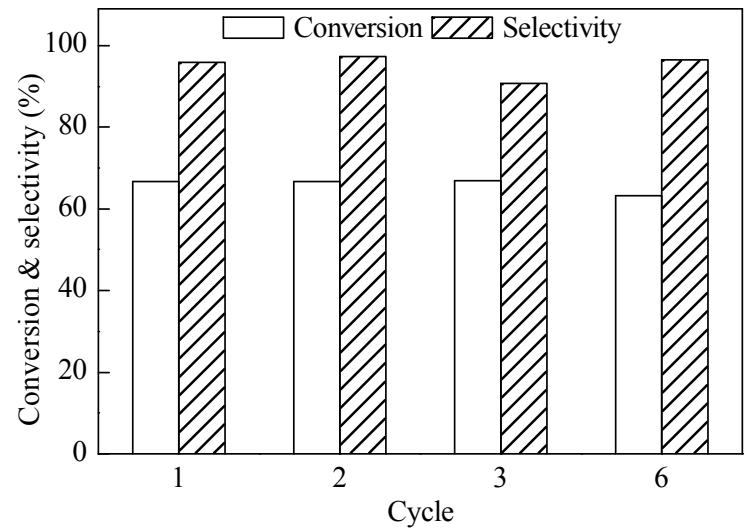

Fig. 10. Recycling of the catalyst $(\mathrm{Mg} / \mathrm{Al}=2)$ in the transesterification of glycerol [50]. Reaction conditions: catalyst $0.45 \mathrm{~g}$, glycerol $43.8 \mathrm{mmol}$ dimethyl carbonate $135 \mathrm{mmol}, \mathrm{CH}_{3} \mathrm{OH} 7 \mathrm{~mL}, 70^{\circ} \mathrm{C}, 3 \mathrm{~h}$.

tive aerobic oxidation of glycerol using molecular oxygen and showed $73 \%$ glycerol conversion with $57 \%$ glyceric acid yield (Fig. 11). Xia et al. [14] reported that the addition of $\mathrm{Ru}$ or $\mathrm{Re}$ enhanced the adsorption and activation of $\mathrm{H}_{2}$ on the surface of the catalysts, which resulted in excellent performance for the hydrogenolysis of biomass-derived glycerol under mild conditions.

Even though much effort has been given to improve the catalyst activity for transesterification, the reusability of the catalyst is generally low. The deactivation of the catalysts during the transesterification reaction may be attributed to the loss of basic sites on the surface of the catalyst and the adsorption of products, which makes catalyst regeneration hard. Structured catalysts with a suitable pore size and reusability should be paid more attention.

Many other catalytic applications for LDHs and their derivatives have also been widely reported in recent years, such as catalysis for the aerobic oxidation of alcohols [62,63], catalytic aldol condensation $[64,65]$, and as catalysts for biomass utilization $[66,67]$ and decomposition of pollutants $[68,69]$.

\section{Conclusions and perspectives}

We briefly introduced the synthesis methods of LDHs with focus on their catalytic applications for hydrogen production and a biorefinery. The several important observations made are summarized as follows.

LDHs have a unique lamellae structure and special properties. Therefore, they can be widely applied in many fields. The investigation of their structure and the relationship between their morphology and catalytic performance is significant for the design of new materials.

LDHs and their derivates exhibited excellent catalytic performance for hydrogen production and a biorefinery, which was attributed to their special structure with high dispersion of active centers, medium basicity, and suitable pore size. Meanwhile, there are many factors that affect the structure-activity relationship of the catalyst. Therefore, more efforts should been given to this field.

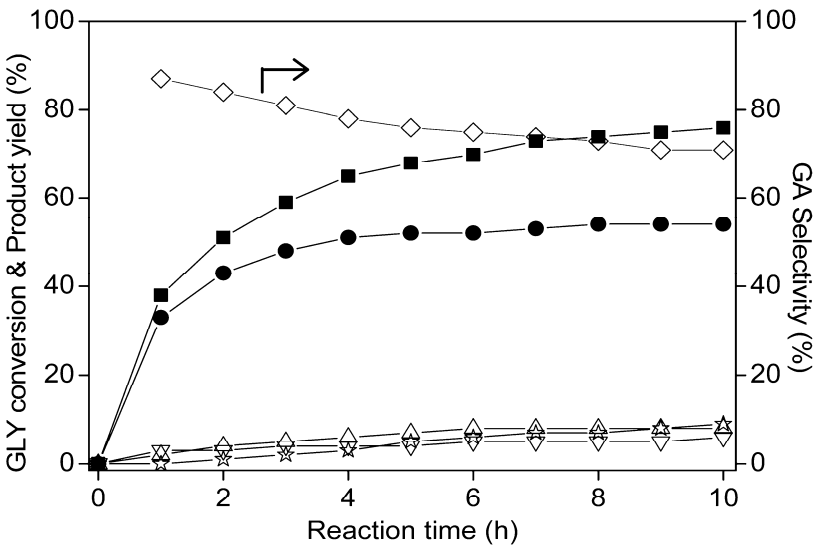

Fig. 11. Glycerol conversion, product yield, and glyceric acid (GA) selectivity versus time on stream. Glycerol conversion ( $\mathbf{})$, GA yield $(\bullet)$, tartronic acid yield $(\Delta)$, glycolic acid yield $(\nabla)$, oxalic acid yield ( $(\tau)$ ), and GA selectivity $(\diamond)$. Reaction conditions: Glycerol $0.5 \mathrm{mmol}, \mathrm{H}_{2} \mathrm{O} 2 \mathrm{~mL}$, catalyst $20 \mathrm{mg}$, oxygen flow $10 \mathrm{~mL} / \mathrm{min}, 25^{\circ} \mathrm{C}$. Reprinted with permission from Ref. [61]. Copyright 2013 American Chemical Society.

As heterogeneous basic catalysts, LDHs and their derivates demonstrated special advantages compared to conventional homogeneous catalysts, which have severe pollution and corrosion problems. However, the reusability and stability of LDH related catalysts need to be further improved. The design of LDHs with one or two active components including a transition metal or noble metal has been widely studied. However, there are less comprehensive studies on the synergic interaction of the active components and the synergistic catalytic mechanism, which effectively promote the catalytic activity and are significant for the rational design of new catalysts with special structure and active components. In the future, more efforts should be given to the synthesis and application of LDH related catalysts with multiple components and high activity in the green chemical industry.

\section{Acknowledgments}

The authors gratefully acknowledge Bo Xu, Jing Huang, and Yanyan Feng at Sichuan University for useful discussions.

\section{References}

[1] Teramura K, Iguchi S, Mizuno Y, Shishido T, Tanaka T. Angew Chem, 2012, 124: 8132

[2] Wang Q, O'Hare D. Chem Rev, 2012, 112: 4124

[3] Qiao D, Xu C L, Xu J. Catal Commun, 2014, 45: 44

[4] Nagashima K, Mitsudome T, Mizugaki T, Jitsukawa K, Kaneda K. Green Chem, 2010, 12: 2142

[5] Álvarez M G, Chimentão R J, Figueras F, Medina F. Appl Clay Sci, 2012, 58: 16

[6] Alanis C, Natividad R, Barrera-Diaz C, Martinez-Miranda V, Prince J, Valente J S. Appl Catal B, 2013, 140-141: 546

[7] Parida K, Satpathy M, Mohapatra L. J Mater Chem, 2012, 22: 7350

[8] Xia S J, Liu F X, Ni Z M, Shi W, Xue J L, Qian P P. Appl Catal B, 2014, 144: 570

[9] Omwoma S, Chen W, Tsunashima R, Song Y F. Coordin Chem Rev, 2014, 258-259: 58 
[10] Gunjakar J L, Kim T W, Kim H N, Kim I Y, Hwang S J. J Am Chem Soc, 2011, 133: 14998

[11] Yu X P, Wang N, Chu W, Liu M. Chem Eng J, 2012, 209: 623

[12] Gomes J F P, Puna J F B, Goncalves L M, Bordado J C M. Energy, 2011, 36: 6770

[13] Yan K, Wu X, An X, Xie X M. Chem Eng Commun, 2014, 201: 456

[14] Xia S X, Zheng L P, Nie R F, Chen P, Lou H, Hou Z Y. Chin J Catal (夏 水釒金, 郑丽萍, 聂仁峰, 陈平, 楼辉, 侯昭)乣. 催化学报), 2013, 34: 986

[15] Vulic T, Reitzmann A, Ranogajec J, Marinkovic-Neducin R. J Therm Anal Calorim, 2012, 110: 227

[16] Heredia A C, Oliva M I, Agú U, Zandalazini C I, Marchetti S G, Herrero E R, Crivello M E. J Magn Magn Mater, 2013, 342: 38

[17] Herrero M, Labajos F M, Rives V. Appl Clay Sci, 2009, 42: 510

[18] Resini C, Montanari T, Barattini L, Ramis G, Busca G, Presto S, Riani P, Marazza R, Sisani M, Marmottini F, Costantino U. Appl Catal A, 2009, 355: 83

[19] Yu X P, Chu W, Wang N, Ma F. Catal Lett, 2011, 141: 1228

[20] Jing F L, Zhang Y Y, Luo S Z, Chu W, Qian W Z. Appl Clay Sci, 2010, 48: 203

[21] Fernández Y, Menéndez J A, Arenillas A, Fuente E, Peng J H, Zhang Z B, Li W, Zhang Z Y. Solid State Ionics, 2009, 180: 1372

[22] Deng X, Fang Z, Liu Y H, Yu C L. Energy, 2011, 36: 777

[23] Chakraborty C, Dana K, Malik S. J Phys Chem C, 2011, 115: 1996

[24] Menezes J, da Silva T, dos Santos J, Catari E, Meneghetti M, da Matta C, Alexandre-Moreira M, Santos-Magalhães N, Grillo L, Dornelas C. Appl Clay Sci, 2014, 91-92: 127

[25] Kutlu B, Leuteritz A, Boldt R, Jehnichen D, Heinrich G. Chem Eng J, 2014, 243: 394

[26] Sun W, Wang X L, Zhao Z H, Ding K Q, Liu X F, Wu G D. J Mol Catal (China) (孙雯, 王晓丽, 赵振华, 丁克强, 刘献锋, 吴功德. 分子催 化), 2013, 27: 37

[27] Hu G, O'Hare D. J Am Chem Soc, 2005, 127: 17808

[28] Mendoza-Damian G, Tzompantzi F, Mantilla A, Barrera A, Lartundo-Rojas L.J Hazard Mater, 2013, 263P: 67

[29] Zhang H, Alhamed Y A, Chu W, Ye Z B, AlZahrani A, Petrov L. Appl Catal A, 2013, 464-465: 156

[30] Tong D G, Tang D M, Chu W, Gu G F, Wu P. J Mater Chem A, 2013, 1 : 6425

[31] Broda M, Manovic V, Imtiaz Q, Kierzkowska A M, Anthony E J, Müller C R. Environ Sci Technol, 2013, 47: 6007

[32] Chanburanasiri N, Ribeiro A M, Rodrigues A E, Laosiripojana N, Assabumrungrat S. Energy Fuels, 2013, 27: 4457
[33] Nagaoka K, Jentys A, Lercher J A.J Catal, 2005, 229: 185

[34] Halabi M H, de Croon M H J M, van der Schaaf J, Cobden P D, Schouten J C. Chem Eng J, 2011, 168: 872

[35] Takehira K, Shishido T, Wang P, Kosaka T, Takaki K. J Catal, 2004, 221: 43

[36] Cesar D V, Baldanza M A S, Henriques C A, Pompeo F, Santori G, Múnera J, Lombardo E, Schmal M, Cornaglia L, Nichio N. Int J Hydrogen Energy, 2013, 38: 5616

[37] Basile F, Benito P, Fornasari G, Vaccari A. Appl Clay Sci, 2010, 48: 250

[38] Tanasoi S, Tanchoux N, Urdă A, Tichit D, Săndulescu I, Fajula F, Marcu I C. Appl Catal A, 2009, 363: 135

[39] Cunha A F, Wu Y J, Santos J C, Rodrigues A E. Chem Eng Res Des, 2013, 91: 581

[40] Tang Y, Liu Y, Zhu P, Xue Q S, Chen L, Lu Y. AIChE J, 2009, 55: 1217

[41] Zhang C X, Zhang P, Li S R, Wu G W, Ma X B, Gong J L. Phys Chem Chem Phys, 2012, 14: 3295

[42] Cunha A F, Wu Y J, Santos J C, Rodrigues A E. Ind Eng Chem Res, 2012, 51: 13132

[43] Cunha A F, Wu Y J, Li P, Yu J G, Rodrigues A E. Ind Eng Chem Res, 2014, 53: 3842

[44] Montañez M K, Molina R, Moreno S. Int J Hydrogen Energy, 2014, 39: 8225

[45] Huang L H, Liu Q, Chen R R, Chu D, Hsu A T. Catal Commun, 2010, 12: 40

[46] Zhang T, Corma A, Schüth F. Chin J Catal (张涛, Corma A, Schüth F. 催化学报), 2014, 35: 601

[47] Lee H V, Juan J C, Binti Abdullah N F, Nizah Mf R, Taufiq-Yap Y H. Chem Cent J, 2014, 8: 30

[48] Silva C C C M, Ribeiro N F P, Souza M M V M, Aranda D A G. Fuel Process Technol, 2010, 91: 205

[49] Martins M I, Pires R F, Alves M J, Hori C E, Reis M H M, Cardoso V L. Chem Eng Trans, 2013, 32: 817

[50] Zheng L P, Xia S X, Hou Z T, Zhang M Y, Hou Z Y. Chin J Catal (郑丽 萍, 夏水釒金, 侯召同, 张梦媛, 侯昭胤. 催化学报), 2014, 35: 310

[51] Liu Q H, Wang B C, Wang C X, Tian Z J, Qu W, Ma H J, Xu R S. Green Chem, 2014, 16: 2604

[52] Helwani Z, Aziz N, Bakar M Z A, Mukhtar H, Kim J, Othman M R. Energy Convers Manag, 2013, 73: 128

[53] Wang S H, Wang Y B, Dai Y M, Jehng J M. Appl Catal A, 2012, 439-440: 135

[54] Wang Y B, Jehng J M. Chem Eng J, 2011, 175: 548

[55] Gao L J, Teng G Y, Xiao G M, Wei R P. Biomass Bioenergy, 2010, 34:

\section{Graphical Abstract}

Chin. J. Catal., 2015, 36: 139-147 doi: 10.1016/S1872-2067(14)60229-1

\section{Layered double hydroxide and related catalysts for hydrogen production and a biorefinery}

Wei Wang, Zhenxin Xu, Zhanglong Guo, Chengfa Jiang, Wei Chu* Sichuan University

Homogeneously dispersed nano-metal oxides can be obtained by the controlled thermal decomposition of layered double hydroxide precursors. These catalysts have many advantages, such as high specific surface areas, basic character, high dispersion of the active centers and thermal stability against sintering. They exhibit excellent catalytic activity for hydrogen production.

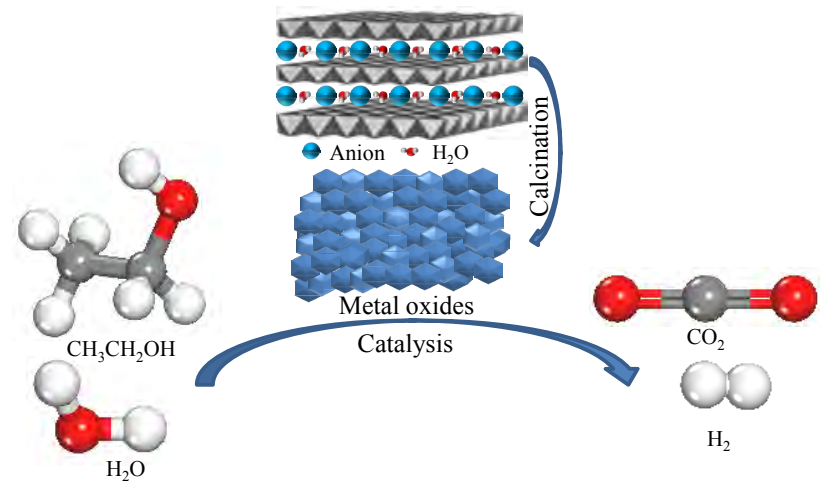


1283

[56] Reyero I, Velasco I, Sanz O, Montes M, Arzamendi G, Gandía L M. Catal Today, 2013, 216: 211

[57] Liu P, Derchi M, Hensen E J M. Appl Catal A, 2013, 467: 124

[58] Xu C L, Gao Y, Liu X H, Xin R R, Wang Z. RSC Adv, 2013, 3: 793

[59] Alvarez M G, Segarra A M, Contreras S, Sueiras J E, Medina F, Figueras F. Chem Eng J, 2010, 161: 340

[60] Liu P, Derchi M, Hensen E J M. Appl Catal B, 2014, 144: 135

[61] Tongsakul D, Nishimura S, Ebitani K. ACS Catal, 2013, 3: 2199

[62] Baskaran T, Kumaravel R, Christopher J, Sakthivel A. RSC Adv, 2014, 4: 11188

[63] Wang L, Meng X J, Xiao F S. Chin J Catal (王亮, 孟祥举, 肖丰收. 催
化学报), 2010, 31: 943

[64] Hora L, Kelbichová V, Kikhtyanin O, Bortnovskiy O, Kubička D. Catal Today, 2014, 223: 138

[65] Yadav G D, Aduri P.J Mol Catal A, 2012, 355: 142

[66] Li D L, Wang L, Koike M, Nakagawa Y, Tomishige K. Appl Catal B, 2011, 102: 528

[67] Zheng M Y, Pang J F, Wang A Q Zhang T. Chin J Catal (郑明远, 庞纪 峰, 王爱琴, 张涛. 催化学报), 2014, 35: 602

[68] Sui M H, Duan B B, Sheng L, Huang S H, She L. Chin J Catal (隋铭皓, 段标标, 盛力, 黄书杭, 余否. 催化学报), 2012, 33: 1284

[69] Cheng H K, Huang Y Q, Wang A Q, Li L, Wang X D, Zhang T. Appl Catal B, 2009, 89: 391

\title{
水滑石类催化剂催化制氢及生物炼制
}

\author{
王 伟 ${ }^{\mathrm{a}, \mathrm{b}}$, 徐振新 ${ }^{\mathrm{a}}$, 郭章龙 ${ }^{\mathrm{a}, \mathrm{b}}$, 江成发 ${ }^{\mathrm{a}}$, 储 伟 ${ }^{\mathrm{a}, \mathrm{b},{ }^{*}}$ \\ ${ }^{\mathrm{a}}$ 四川大学化学工程学院, 四川成都610065 \\ $\mathrm{b}$ 四川大学四川省环境保护催化与材料工程研究中心, 四川成都610064
}

摘要: 近年来, 水滑石由于其独特的性质受到越来越多的关注. 作为非均相固体催化剂, 水滑石及其衍生物具有优良的催化性能, 因此得到了广泛研究和应用. 本文简述了水滑石的几种合成方法, 重点介绍了水滑石类催化剂在催化制氢和生物炼制方面的应 用, 并预测了水滑石类材料在新材料合成及环境友好催化体系中的应用前景.

关键词: 水滑石; 非均相催化剂; 水蒸气重整; 制氢; 生物炼制; 酯交换反应

收稿日期: 2014-06-28. 接受日期: 2014-09-16. 出版日期: 2015-02-20.

*通讯联系人. 电话: (028)85403836; 传真: (028)85461108; 电子信箱: chuwei1965@scu.edu.cn, chuwei1965scu@163.com

基金来源：国家重点基础研究发展计划(973计划, 2011CB201202).

本文的英文电子版由Elsevier出版社在ScienceDirect上出版(http://www.sciencedirect.com/science/journal/18722067). 